\title{
Microcanuella bisetosa gen. n., sp. n., a new taxon of Canuellidae (Crustacea, Copepoda) from the Costa Rican Pacific coast, with remarks on Galapacanuella beckeri
}

\author{
Wolfgang Mielke \\ II. Zoologisches Institut und Museum der Universität Göttingen, Berliner Straße 28, D-37073 Göttingen, \\ Germany
}

Keywords: Microcanuella, systematics of Canuellidae, Costa Rica, Galapacanuella

\begin{abstract}
A new canuellid, Microcanuella bisetosa gen. n., sp. n., was collected on the Pacific coast (Gulf of Nicoya) of Costa Rica. Though the male is still unknown, a new genus is established, mainly because of the reduced armature of P1, P4, and P5. The small-sized $M$. bisetosa sp. $\mathrm{n}$. is a mesopsammic species, inhabiting the interstices of coarse sediments of a beach slope.
\end{abstract}

\section{Zusammenfassung}

An der Pazifikküste (Golf von Nicoya) von Costa Rica wurde ein neuer Canuellide, Microcanuella bisetosa gen. n., sp. n., gesammelt. Das auffallendste Merkmal ist die reduzierte Bewehrung von P1, P4 und P5. Es wurde daher eine neue Gattung errichtet, obwohl das Männchen noch unbekannt ist. Die vergleichweise kleine $M$. bisetosa sp. n. gehört zum Mesopsammon und bewohnt die Lückenräume des groben Sedimentes eines Strandes.

\section{Introduction}

The Canuellidae are supposed to represent the most primitive copepods (e.g. Lang, 1948; Por, 1984). Many recent canuellid species have retained the presumably original epibenthic life. Nevertheless, the taxon includes representatives with a changed mode of existence. Some species (Sunaristes, Canuella, Brianola?) live in loose or even close association with hermit crabs (Ho, 1988). Other canuellids - like the here described Costa Rican species - apparently succeeded in settling the interstices of coarse sediments in sandy beaches.

\section{Material and methods}

Four females were collected in the beach slope of Punta Morales, situated at the east coast of the Gulf of Nicoya on the Pacific side of Costa Rica (see Mielke, 1992). The animals were washed from the sediment and fixed in a $4 \%$ formalin/seawater solution. Two females were dissected on slides in W 15 medium (Zeiss); the cover glass was sealed with Eukitt and DePeX. All drawings were made with the aid of a camera lucida. The material is deposited in the collections of the Zoological Museum of the University of Göttingen.

\section{Systematic account}

Canuellidae Lang, 1948

Microcanuella gen. $\mathrm{n}$.

Diagnosis. - Body comparatively small, clearly less than $1 \mathrm{~mm}$. Genital double-somite incompletely subdivided. Furcal rami slender, about 4 times longer than wide. Antenna 15 -segmented. Exopodite of antenna 2 with basal socle, 6-segmented. All rami of P1-P4 3-segmented. Seta and spine formula reduced, in particular in P4, bearing only 2 setae on distal segments of exo- and endopodite. P5 small, only having 3 setae. Male unknown. Monotypic.

Type species. - Microcanuella bisetosa sp. $\mathrm{n}$.

Etymology. - The name of the new genus is composed of micro meaning small (alluding to body 
W. Mielke - Microcanuella bisetosa gen. n., sp. $n$.

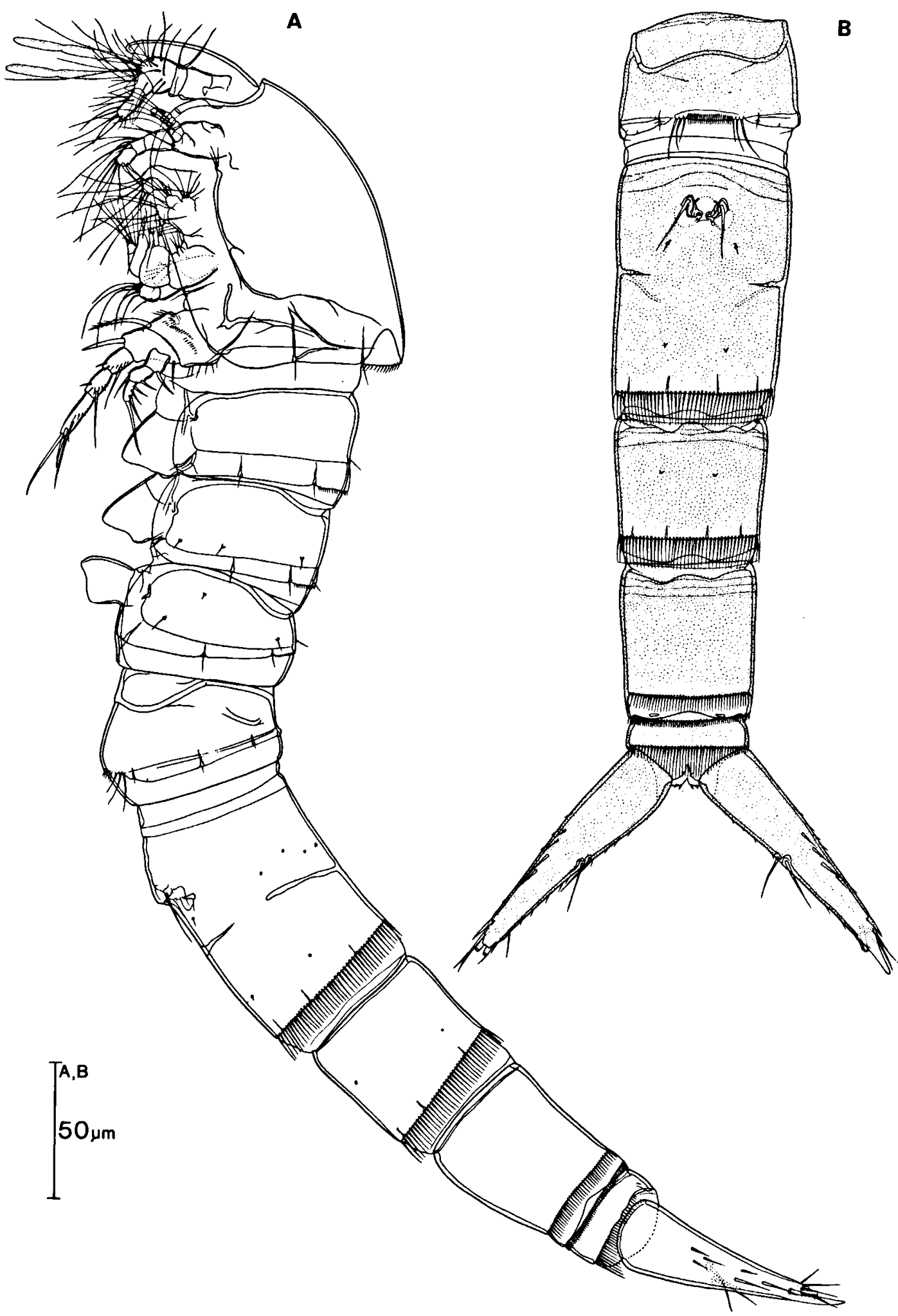

Fig. 1. Microcanuella bisetosa sp. n., $९$ : A, habitus, lateral; B, last pereiomere and abdomen, ventral. 
size), and the existing generic name Canuella. The species name refers to the presence of only 2 setae on the distal segments of exo- and endopodite of P4.

Microcanuella bisetosa sp. n. (Figs. 1-6)

Type material. - Four females from Costa Rica, Punta Morales, 29 August 1990 (corresponds with locality 4 in Mielke, 1992). Two animals were dissected. Holotype: female, reg. no. I CR 120. Paratypes: other dissected female (I CR 119) and two undissected specimens (I CR 119A, 119B).

Rostrum + antenna 1, mandible, P2 through P5, and dorsal caudal part of the body are drawn from the holotype.

Description. - Female: Body length of two dissected animals from tip of rostrum to end of furcal rami $0.56 \mathrm{~mm}$ (holotype) and $0.60 \mathrm{~mm}$ (paratype). Rostrum well developed, tongue-like elongated, seemingly articulating with cephalothorax (Fig. 4A). Somite of P1 apparently incorporated in cephalothorax (consisting of head and two thoracic somites, bearing maxilliped and P1). Genital double-somite subdivided by a dorsolateral stripe. Genital area with 2 slender setae (Fig. 1B). Dorsal caudal margin of cephalothorax and following pereiomeres 2-4 with short spinules. Surface of abdominal somites with pitted pattern. Caudal edge of genital double-somite and following somites with row of spinules. Row on penultimate somite weaker, and additional terminal row of short spinules present. Anal somite short, bearing long spinules ventrally and small spinules laterally and dorsally. The anal somite is interpreted as having an anal operculum, subdistally with fine setules; the existence of an additional pseudoperculum cannot be excluded. Furcal rami diverging, 3.5-4 times longer than wide, distally slightly tapering. Surface of rami with pitted pattern; furthermore with several hyaline setules, difficult to discern because they mostly cling to the rami. On outer edge of right furcal ramus of holotype, one hyaline setule is loose (Fig. 2A). Two slender setae about at middle of inner margin, and another subdistally. Furcal rami with distal spiniform process. In both dissected animals both principal setae broken off. Inner principal seta accompanied by short setule. Near outer seta, holotype bears 3 , the dissected paratype seemingly only 2 setae ( 1 broken off?). Furthermore, short spine subapically on outer edge (see Figs. 1A, B; 2A).

Antenna 1 (Fig. 4A). Short and compact, apparently consisting of 5 segments. Two aesthetascs on third segment; both pinched in distal part. Several setae plumose.

Antenna 2 (Fig. 2B). Basis with a row of small spinules. Endopodite 3-segmented. Basal segment with 1 seta on surface and 1 seta in middle of anterior edge; segment 2 with 2 setae on anterior edge and 3 setae distally; terminal segment carrying 7 elements of different length. Exopodite 6-segmented, sitting on a socle ("Exopoditensockel" according to Lang, 1948: 46), bearing a plumose seta. Segments $1-5$ each with 1 seta, segment 6 with 3 (probably 4) setae.

Mandible (Fig. 3A). Coxa-basis with 2 plumose setae and some slender spinules. Endopodite 2-segmented. Basal segment with 3, distal segment with 8 setae. Exopodite 3-segmented. Segment 1 with 1, segment 2 with 2 juxtaposed setae, and segment 3 with 3 plumose setae.

Maxilla 1 (Fig. 3B). Arthrite of precoxa with 9 marginal elements and 2 setae on surface. Coxa with 3 (probably 4) medial plumose setae and 3 plumose setae on epipodite. Basis with medial incision, each lobe with 4 setae. Endopodite indistinctly subdivided, bearing 11 setae altogether. Exopodite with 8 setae.

Maxilla 2 (Fig. 4B). Precoxa with 2 endites; proximal endite with 4 setae and 1 small hook; distal endite with 2 setae. Coxa also with 2 endites, each with 3 plumose setae. Basis with 1 claw and 3 setae. Furthermore, 1 long slender seta arising basally from weak articulation line between basis and endopodite; it probably belongs to the basis. Endopodite vaguely segmented, carrying 9 (probably 10 ) setae.

Maxilliped (Fig. 2C). Precoxa and coxa fused, having 10 setae altogether. Basis with some spinules along outer margin and 2 setae on medial margin. Endopodite with 11 setae (some stronger plumose setae accompanied by slender seta).

Pereiopod 1 (Fig. 5A). Coxa with rows of spinules on surface and distal margin; 1 barbed seta on 


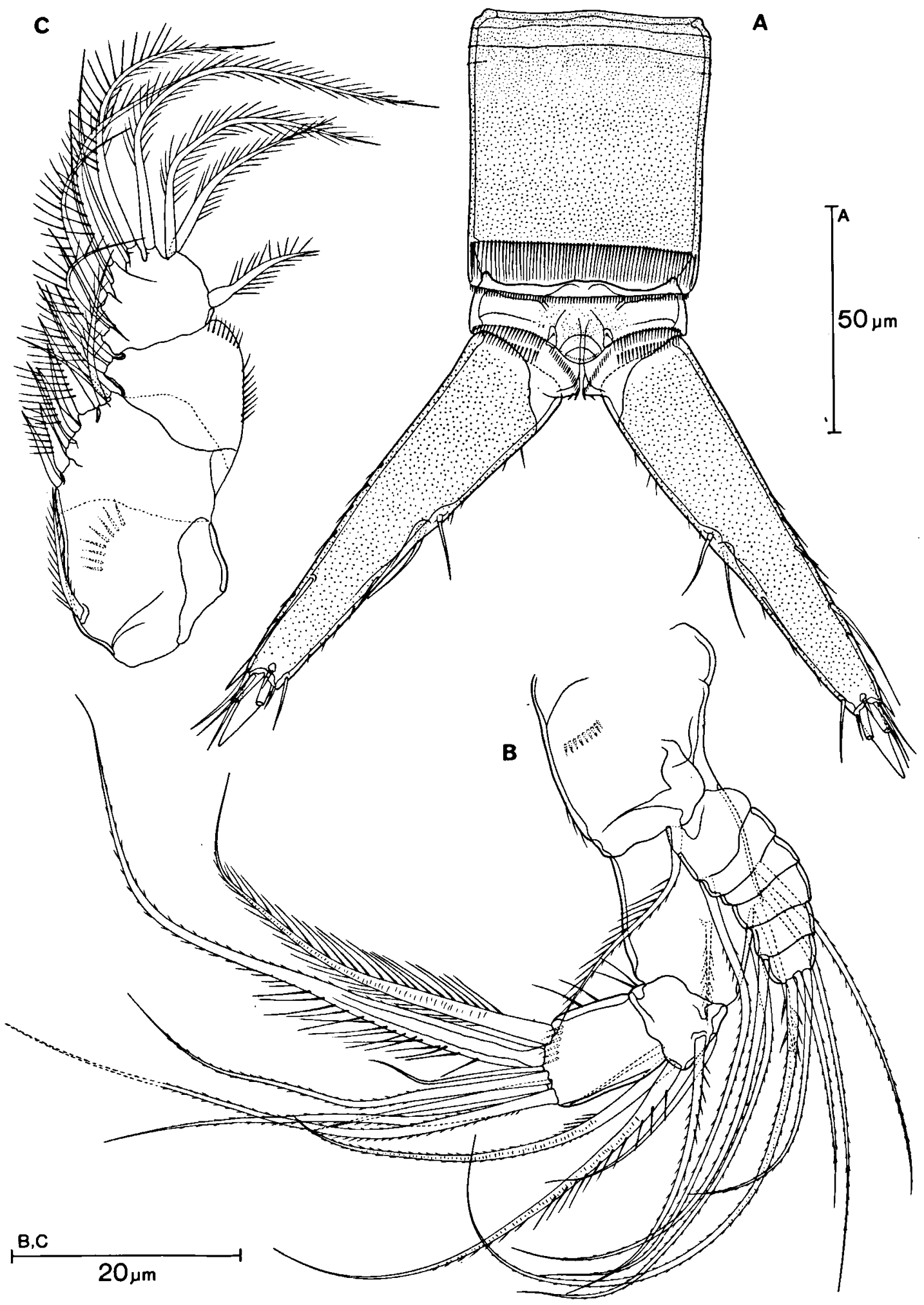

Fig. 2. Microcanuella bisetosa sp. n., \&: A, caudal part of abdomen, dorsal; B, antenna 2; C, maxilliped. 


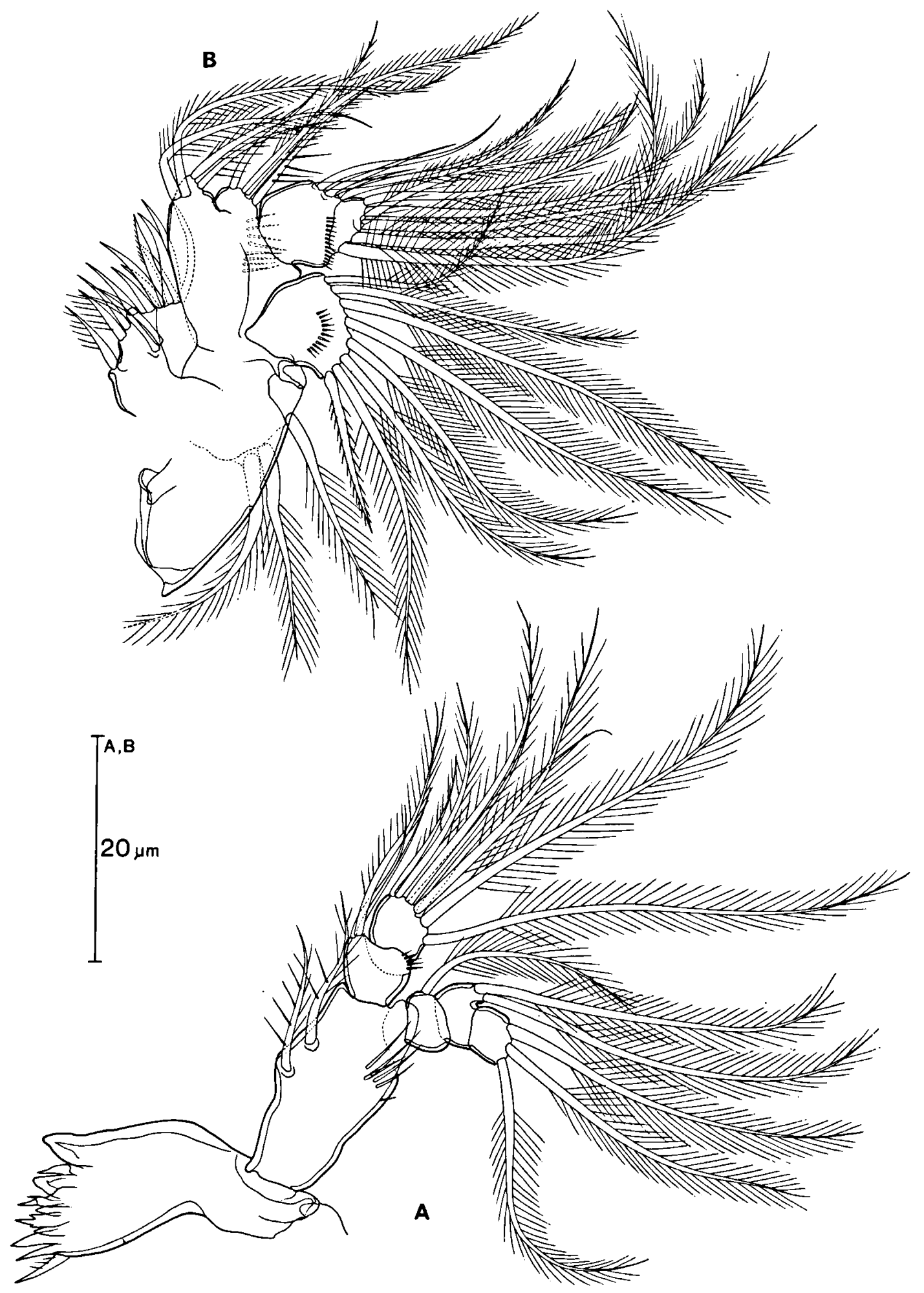

Fig. 3. Microcanuella bisetosa sp. n., ९: A, mandible; B, maxilla 1. 
W. Mielke - Microcanuella bisetosa gen. n., sp. n.

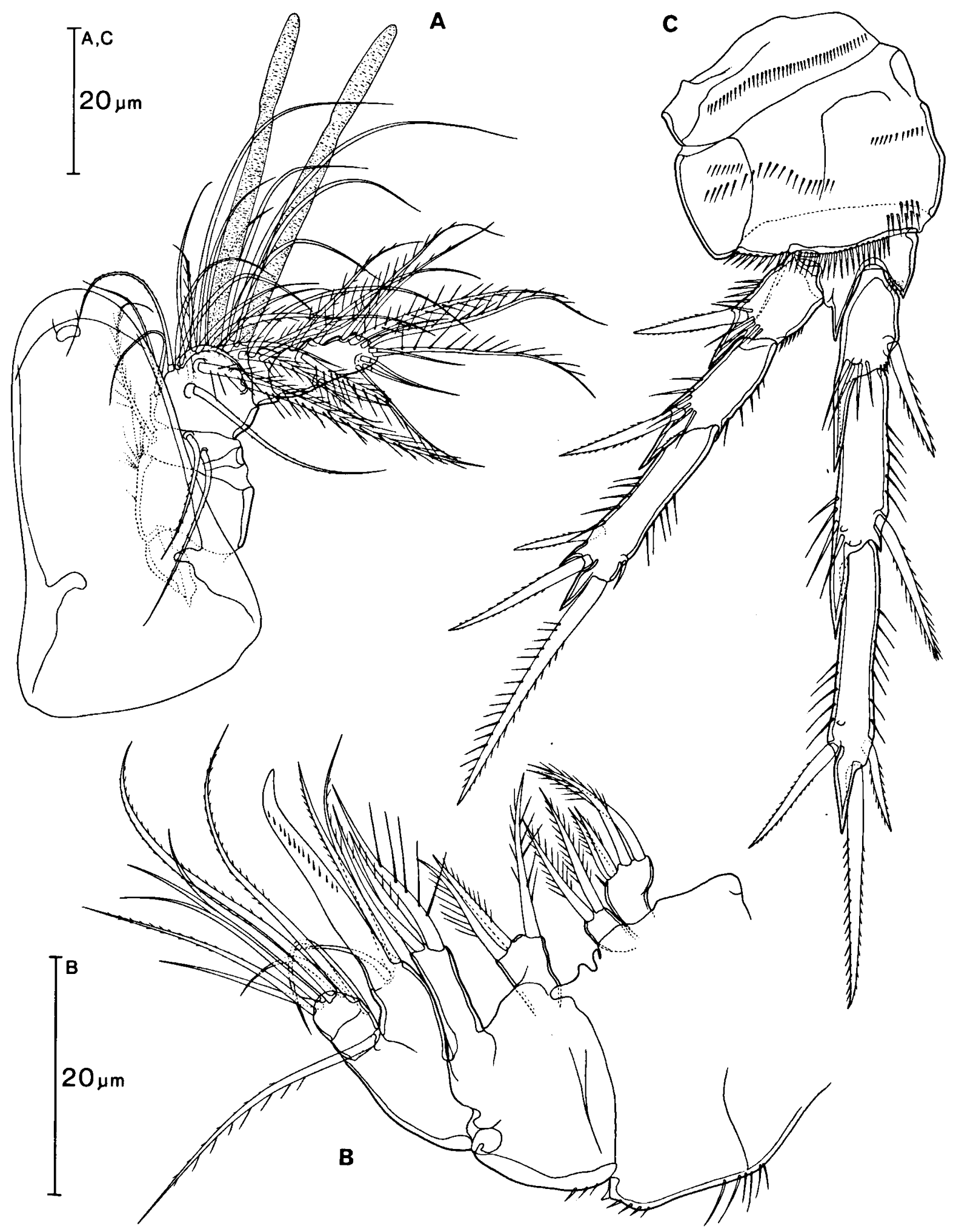

Fig. 4. Microcanuella bisetosa sp. n., ९: A, rostrum and antenna 1; B, maxilla 2; C, P3. 
medial side. Basis with 1 short outer seta and 1 robust inner spine. Endopodite 3-segmented. Basal segment with long spinules on lateral margin, 1 medial seta and apparently one pore on surface. Segment 2 with long spinules on lateral margin and 1 medial plumose seta. Segment 3 with 2 setae and 2 spines. Exopodite 3-segmented. Basal segment with 1 strong lateral spine. Segment 2 with some spinules and 1 plumose seta on median margin; lateral margin with 1 strongly armed spine. Segment 3 bearing 3 lateral spines, 1 long apical seta, and 1 vestigial medial setule.

Pereiopods 2 and 3 (Figs. 5B; 4C). Precoxa (?) with transverse row of spinules. Coxa with several rows of spinules on surface and on distal margin. Basis short, distally prolonged into lateral and central projection; outer edge with 1 short seta. Endopodite 3-segmented, each segment with outer pointed process distally. Segments 1 and 2 with 1 medial seta each; segment 3 with 3 setae. Exopodite 3-segmented. Segments 1 and 2 each with spinules and 1 lateral spine; segment 3 with 1 inner subapical vestigial seta, 1 apical element and 2 outer elements.

Pereiopod 4 (Fig. 5C). Shorter than P2 and P3. Distal segment of exopodite and endopodite only with 2 elements. Segment 1 of endopodite with 1 strong medial seta.

Seta and spine formula:

$\begin{array}{lll} & \text { Exopodite } & \text { Endopodite } \\ \text { P1 } & 0.1 .113 & 1.1 .112 \\ \text { P2 } & 0.0 .112 & 1.1 .111 \\ \text { P3 } & 0.0 .112 & 1.1 .111 \\ \text { P4 } & 0.0 .011 & 1.0 .011\end{array}$

Pereiopod 5 (Fig. 5D) consisting of 3 setae, outer one longest. Between left and right P5 a row of slender spinules.

Male. - Unknown.

\section{Discussion}

The Canuellidae are considered a difficult systematic group within the Copepoda (e.g. Hamond,
1973; Por, 1984). Although Por takes into consideration a "higher hierarchical status" for the family, the transfer to another taxonomic level ("suborder") would not solve the problems; neither does the elevation of genera to "separate families" for Canuellina and Brianola.

The difficulties in analysing the relationships of the canuellid subtaxa are e.g.: (1) many plesiomorphies, which are worthless as phylogenetic evidence (Ax, 1987); (2) apomorphic reduced features, which are sometimes hard to interpret (degree of fusion of the P1-bearing somite, the exact number of segments in antenna 1 and in the exopodites of antenna 2 and mandible); (3) evaluation of various sexually dimorphic characters of the pereiopods. These uncertainties lead to different opinions as to generic status (e.g. Canuella, Scottolana, Brianola) and classification. For example, the species chelicerata was originally described by Por \& Marcus (1972) as a member of the genus Ellucana, then placed in Parasunaristes by Fiers (1982) and in Sunaristes by Por (1984).

Apart from the doubtful monophyly of some genera and their unclear relationships, the Canuellidae as a whole is a well-established monophylum. At least the following autapomorphies can be stressed: (a) Middle segment of the originally 3-segmented endopodite of $\mathbf{P 4}$ at most with a rudimentary seta (exceptions: Canuella elanitica Por, 1967 and $C$. paenelanitica Fiers, 1982). In general this seta is absent. In a further evolutionary step some canuellid species have lost this segment completely. (b) P5 rudimentary in both sexes. (c) The male genital complex. The latter statement, that is the male genital complex representing an autapomorphy, is in clear contradiction to Por's (1984) view, according to which this unique male genital field is a plesiomorphic feature of "phylogenetic importance'. All other copepod taxa then must have lost this structure. It must be emphasized, that the considerable number of plesiomorphies does not exclude the presence of apomorphies in the Canuellidae. Furthermore, Por names this complex "petasma" (adopted e.g. by Fiers, 1984, and Ho, 1986). In accordance with Glatzel (1988) I think that this is inadmissible. The male P6 of the Canuellidae and the petasma of several malacostracan taxa (pleo- 
W. Mielke - Microcanuella bisetosa gen. n., sp. $n$.

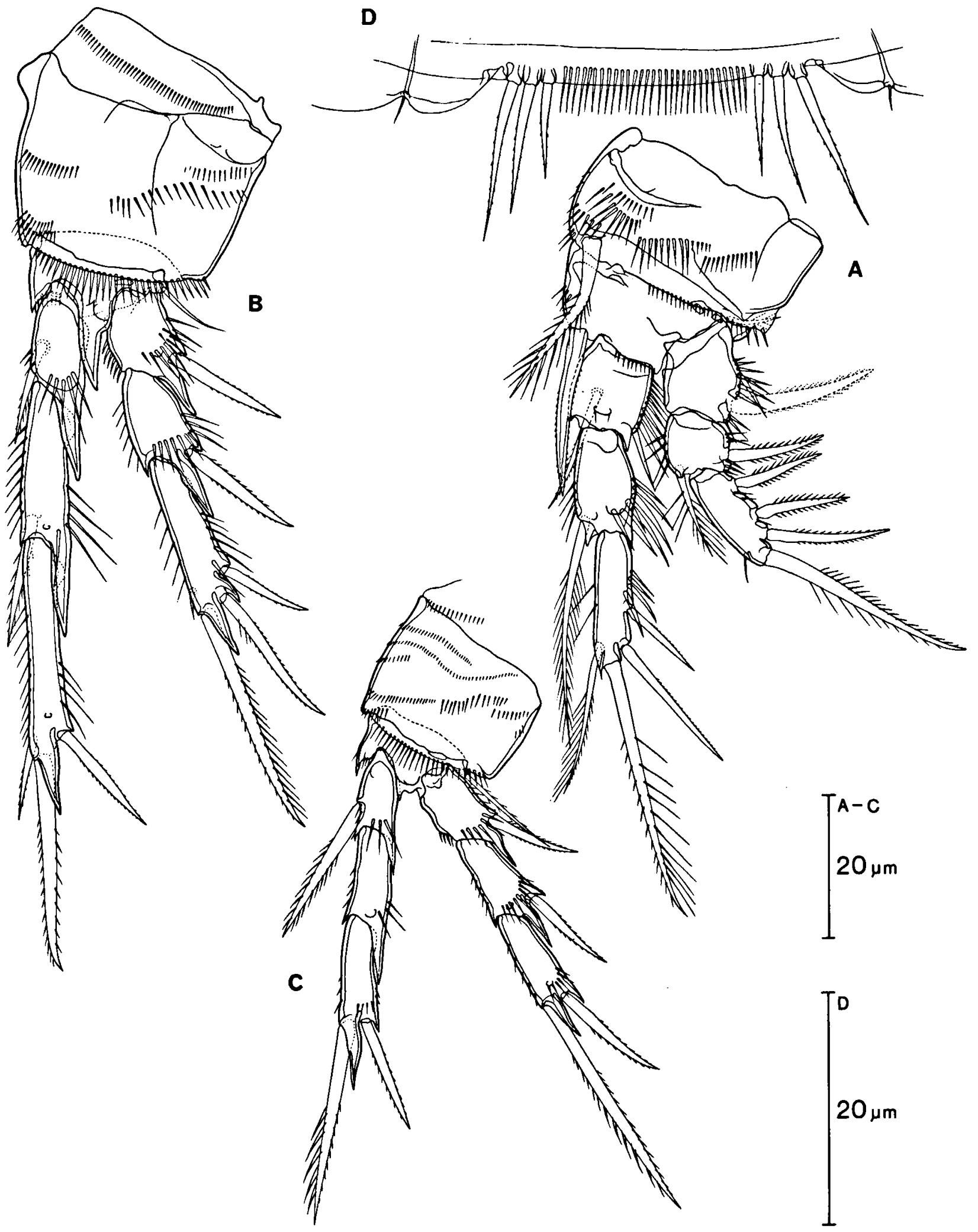

Fig. 5. Microcanuella bisetosa sp. n., ९: A, P1; B, P2; C, P4; D, P5. 


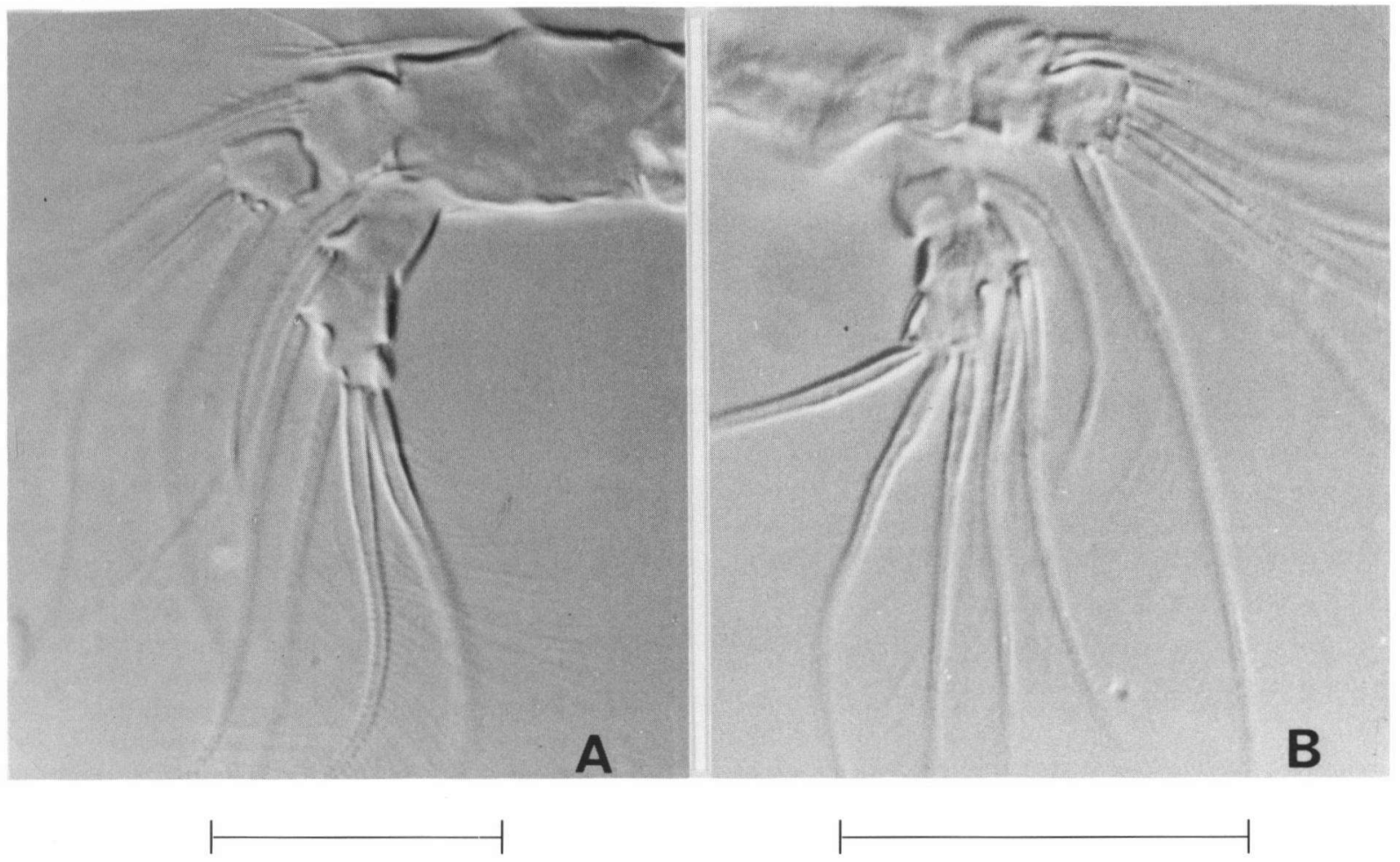

Fig. 6. A, Galapacanuella beckeri Mielke, 1979: mandibular palp, showing setal formula of exopodite 2,1,3; B, Microcanuella bisetosa sp. n.: same, showing formula $1,2,3$ (scale bars $20 \mu \mathrm{m}$ ).

pods 1 and 2 form an auxiliary utensil at copulation) are, in my opinion, at best analogous devices.

Though the male is still unknown, the present Costa Rican species cannot be assigned to any of the known canuellid genera. Therefore the new genus Microcanuella is established with reservations. Remarkable features of this monotypic genus are the small size and the reduced armature of the pereiopods. In particular the P4, with only 2 elements on the terminal segment of exo- and endopodite, and the P5, which bears 3 setae only, are characteristic. The latter character is indeed already known from Sunaristes inaequalis Humes \& Ho, 1969 (variably 3-5 setae), Canuella (Indicanuella) indica Krishnaswamy, 1957, and Galapacanuella beckeri Mielke, 1979. Because of other incompatible features it must be concluded that this reduction took place several times. Close relationships of the new species probably exist with Galapacanuella, which was likewise found in deeper layers of a beach consisting of coarse sediments (Santa Cruz,
Galápagos Islands; see Schmidt, 1978 and Mielke, 1979).

\section{Remarks}

In the description of Galapacanuella beckeri (see Mielke, 1979) the first pereiomere was interpreted as being separated from the cephalothorax. Reexamination revealed that at least ventrolaterally the somites of maxilliped and first pereiomere are divided. In Microcanuella bisetosa sp.n. the fusion appears to be more advanced.

The caudal edge of the penultimate somite of $G$. beckeri was characterized as being smooth but having a striped structure below the surface (shown in Mielke, 1979: fig. 10D, male - not shown in figs. 9A-C, female). However, G. beckeri has a comparable ornamentation of this somite as in the Costa Rican species, i.e., a circular row of thin spinules and an additional terminal row of short spinules. 
As in the present species, in $G$. beckeri both aesthetascs (not only the proximal one) arise from the 3rd segment of antenna 1.

The seta on the anterior edge of the basal segment of the endopodite of antenna 2 is distinctly shorter in $M$. bisetosa sp. $\mathrm{n}$. than in $G$. beckeri. On the other hand, the small distal seta on the second endopodal segment of antenna 2 was overlooked (mostly covered by the terminal segment) in the description of $G$. beckeri.

The distal segment of the endopodite of the mandible carries 7 setae in $G$. beckeri and 8 setae in $M$. bisetosa sp. n. Furthermore, in $G$. beckeri the exopodal segments are furnished with $2,1,3$ setae, whereas the corresponding formula is $1,2,3$ in $M$. bisetosa sp. n. (cf. Figs. 6A, B).

The exopodite of maxilla 1 of $G$. beckeri bears 10 setae, whereas that of $M$. bisetosa has only 8 .

\section{Acknowledgements}

I am very obliged to Dr. M.M. Murillo and Dr. J.A. Vargas (both University of Costa Rica in San José) for their support during my stay in Costa Rica in 1990 . The research trip was made possible by a financial support of the Deutsche Forschungsgemeinschaft (Mi 218/2-3).

\section{References}

Ax, P., 1987. The phylogenetic system. The systematization of organisms on the basis of their phylogenesis: i-xiii, 1-340 (John Wiley \& Sons, Chichester etc.).
Fiers, F., 1982. New Canuellidae from the northern coast of Papua New Guinea (Copepoda: Harpacticoida). Bull. Inst. r. Sci. nat. Belg., 54(4): 1-32, pls. I-XVII.

Fiers, F., 1984. Harpacticoid copepods from the West Indian Islands: Canuellidae and Longipediidae (Copepoda, Harpacticoida). Bijdr. Dierk., 54: 197-210.

Glatzel, T., 1988. The genital fields of Canuella perplexa and C. furcigera (Copepoda, Harpacticoida) - comparative morphology and functional aspects. Bijdr. Dierk., 58: 105-113.

Hamond, R., 1973. Four new copepods (Crustacea: Harpacticoida, Canuellidae) simultaneously occurring with Diogenes senex (Crustacea: Paguridea) near Sydney. Proc. Linn. Soc. New South Wales, 97: 165-201.

Ho, J.-S., 1986. Harpacticoid copepods of the genera Sunaristes and Porcellidium associated with hermit crabs in Japan. Rep. Sado mar. biol. Stat., Niigata Univ., 16: 21-38.

Ho, J.-S., 1988. Cladistics of Sunaristes, a genus of harpacticoid copepods associated with hermit crabs. Hydrobiologia, 167/ 168 (= G.A. Boxshall \& H.K. Schminke eds., Biology of copepods; Developments in Hydrobiology, 47): 555-560.

Lang, K., 1948. Monographie der Harpacticiden, I \& II: 1-1682 (Reprint 1975, Otto Koeltz Sci. Publ., Koenigstein).

Mielke, W., 1979. Interstitielle Fauna von Galapagos. XXV. Longipediidae, Canuellidae, Ectinosomatidae (Harpacticoida). Mikrofauna Meeresboden, 77: 1-106.

Mielke, W., 1992. Six representatives of the Tetragonicipitidae (Copepoda) from Costa Rica. Microfauna Marina, 7: 101146.

Por, F.D., 1984. Canuellidae Lang (Harpacticoida, Polyarthra) and the ancestry of the Copepoda. Crustaceana, Suppl. 7: 124.

Por, F.D. \& A. Marcus, 1972. Copepoda Harpacticoida of the Suez Canal. Isr. J. Zool., 21: 249-274.

Schmidt, P., 1978. Interstitielle Fauna von Galapagos. XXI. Lebensraum, Umweltfaktoren, Gesamtfauna. Mikrofauna Meeresboden, 68: 1-51.

Received: 23 May 1993

Revised: 17 September 1993 